\title{
A cana-de-açúcar em sistema de plantio direto comparado ao sistema convencional com e sem adubação ${ }^{1}$
}

\author{
José B. Duarte Júnior ${ }^{2} \&$ Fábio C. Coelho ${ }^{3}$
}

\begin{abstract}
RESUMO
O objetivo neste trabalho foi avaliar as características agronômicas da cana-de-açúcar em função do sistema de plantio direto (SPD) comparativamente ao convencional (PC) com e sem adubação. O delineamento experimental utilizado foi de blocos casualizados com quatro repetições, em esquema fatorial $4 \times 2$. Os tratamentos foram: cana SPD sobre crotalária (Crotalaria juncea); cana SPD sobre feijão de porco (Canavalia ensiformis); cana SPD sobre mucuna preta (Mucuna aterrima) e cana PC com vegetação espontânea incorporada, sendo duplicados, pois cada um foi com e sem adubação. Em termos nutricionais, a cana SPD sobre leguminosas foi $43 \%$ superior em teores de K, e o destaque foi feijão de porco e mucuna que proporcionaram, em média, $26 \%$ a mais de $\mathrm{N}$ foliar em relação à cana $\mathrm{PC}$. A diagnose nutricional também indicou $\mathrm{N}$ e $\mathrm{K}$ como os principais nutrientes limitantes da produtividade da cana $\mathrm{PC}$, enquanto $\mathrm{Ca}, \mathrm{Fe}, \mathrm{Zn}$ e $\mathrm{Cu}$ foram limitantes independentes do sistema de manejo. O K foi o principal nutriente limitante da produtividade da cana não adubada. O SPD de cana sobre leguminosas proporcionou maiores teores foliares de $\mathrm{N}$ e K, além de aumentar em 27,32 e $37 \%$, respectivamente, o número, o diâmetro e a produtividade de colmos em relação à cana de PC. A canade-açúcar em SPD sobre palhada de leguminosas garante, além de ser mais produtiva, maior preservação do ambiente devido à colheita da cana sem prévia queimada.
\end{abstract}

Palavras-chave: Saccharum sp., sustentabilidade da agricultura, adubo verde

\section{Sugarcane in a no-tillage system compared to the conventional system with, and without, manuring}

\begin{abstract}
The objective of this study was to evaluate the agronomic characteristics of sugarcane as a function of the no-tillage system (NTS) compared to the conventional one (CS) with, and without, manuring. The experimental design was completely randomized, using four repetitions, in a factorial scheme $4 \times 2$. The treatments were: sugarcane NTS on sunnhemp (Crotalaria juncea); sugarcane NTS on jack bean (Canavalia ensiformis); sugarcane NTS on black mucuna (Mucuna aterrima) and sugarcane CS with incorporation of spontaneous vegetation (control), being duplicated, since each one was with, and without, manuring. In nutritional terms, the sugarcane CS on leguminosae was $43 \%$ superior in content of $\mathrm{K}$, and the prominence was jack bean and mucuna that on average provided $26 \%$ more foliar $\mathrm{N}$ in relation to sugarcane $\mathrm{CS}$. The nutritional diagnosis also indicated $\mathrm{N}$ and $\mathrm{K}$ as the main limitants of the productivity of sugarcane CS, while $\mathrm{Ca}$, $\mathrm{Fe}, \mathrm{Zn}$ and $\mathrm{Cu}$ were independent limitants of the management system. $\mathrm{K}$ was the main nutrient limitant of the productivity of unfertilized sugarcane. Sugarcane NTS on leguminosae provides larger foliar contents of N and K, besides increasing in 27,32 and $37 \%$, respectively, the number, the diameter and the productivity of stems in relation to the sugarcane of CS. The sugarcane in NTS on leguminosae, besides being more productive, guarantees larger preservation of the environment due to the harvesting of the cane without prior burning.
\end{abstract}

Key words: Saccharum sp., sustainable agriculture, green fertilizer

1 Parte do Trabalho de Tese de Doutorado do primeiro autor da Universidade Estadual do Norte Fluminense Darcy Ribeiro

2 LFIT/UNIOESTE, Setor de Grandes Culturas, Rua Pernambuco, 1777, CEP 85960-000, Marechal Cândido Rondon, PR. Fone: (45) 3284-7901, E-mail: bduarte7@yahoo.com.br

3 LFIT/UENF, Av. Alberto Lamego, 2000, CEP 28013-620, Campos dos Goytacazes, RJ. Fone: (22) 2726-1426, E-mail: fcoelho@uenf.br 


\section{INTRODUÇÃO}

O Brasil colhe 440 milhões de toneladas de cana-de-açúcar em aproximadamente seis milhões de hectares, com produtividade média de 74 ton ha-1 (CONAB, 2005). Na região Sudeste do Brasil a cana-de-açúcar é uma cultura de grande importância, tanto social como economicamente. O estado do Rio de Janeiro responde por apenas $1,6 \%$ da produção nacional (CONAB, 2005), os níveis de produtividade ainda são baixos, em torno de 45 ton ha ${ }^{-1}$, em virtude do manejo inadequado solo com o preparo convencional causando erosão de partículas e lixiviação dos nutrientes, dos cultivos sem adubação, do uso de variedades com baixo potencial produtivo e da queimada prévia da cana para a colheita.

Ao avaliarem o estado nutricional de lavouras canavieiras na região Norte Fluminense no município de Campos dos Goytacazes, Reis Jr. \& Monnerat (2002), constataram que as diagnoses nutricionais de padrões calibrados regionalmente (teores adequados e DRIS) indicaram $\mathrm{K}, \mathrm{P}$ e $\mathrm{S}$ como os principais nutrientes limitantes, enquanto as diagnoses nutricionais de padrões descritos na literatura indicaram N, Zn e Cu como os principais nutrientes limitantes. Assim, é importante ressaltar que, independente do método com que se avaliou o estado nutricional da cana nessa região, constatou-se que há vários nutrientes limitando a produtividade da cultura, principalmente $\mathrm{N}, \mathrm{P}$ e K, e evidenciando os efeitos negativos da falta de adubação, da aplicação de fertilizantes de maneira não racional, que visem a aumentos de produtividade, e do manejo inadequado do solo com o preparo convencional e a colheita da cana queimada. Canellas et al. (2003) verificaram, na camada superficial do solo $(0-20 \mathrm{~cm})$ que o teor de carbono variou de $13,13 \mathrm{~g} \mathrm{~kg}^{-1}$, na cana queimada a $22,34 \mathrm{~g} \mathrm{~kg}^{-1}$, na cana crua, indicando a melhoria nos atributos químicos do solo com a colheita da cana crua, o que foi indicado também por Mendonza et al. (2000). A colheita da cana queimada promove, ainda, a degradação de outras propriedades do solo, evidenciada pela redução do diâmetro médio ponderado dos agregados estáveis e pelo aumento da densidade do solo na profundidade de zero a cinco centímetros, com conseqüente diminuição da velocidade de infiltração instantânea da água no solo (Ceddia et al., 1999).

As características químicas e físicas do solo podem ser melhoradas através do manejo adequado do solo e da cultura da cana-de-açúcar envolvendo a utilização de sistemas conservacionistas (Andrioli et al., 1997; Bianchini et al., 2001), o plantio direto, que proporciona comprovadas melhorias nas condições de fertilidade do solo (Santos et al., 1995; Franchini et al., 2000), é eficiente alternativa em acumular matéria orgânica no solo e contribuir para o seqüestro do $\mathrm{CO}_{2}$ atmosférico em solos agrícolas e, portanto, para a melhoria da qualidade ambiental (Amado et al., 2001). De médio, em longo prazo, o sistema de plantio direto favorece o maior acúmulo de palha na superfície do solo (Barcelos et al., 1999), maior percentagem de agregados nas classes de maior diâmetro (da Ros et al., 1996; Carvalho et al., 1999), menor desagregação do solo, maior retenção de água (Carvalho et al., 1999), maiores taxas de infiltração de água no solo (Barcelos et al., 1999), redução superior a 99\% nas perdas de solo e 94\% nas perdas de água (Seganfredo et al., 1997), menores temperaturas máximas e flutuação térmica do solo (Amado et al., 1990), menor evaporação da água do solo (Freitas et al., 2004), maior economia de água de irrigação em torno de 14\% (Andrade et al., 2002), em relação ao preparo convencional com o solo descoberto ou sem palhada na superfície do solo, além do plantio direto na canade-açúcar proporcionar redução no número de operações, tempo disponível de pessoal e equipamentos envolvidos, custos em aproximadamente $47 \%$ em comparação com o convencional e ainda pode aumentar a produtividade (Dalben et al., 1983; Cruz, 2003).

A entrada externa de nutrientes para os sistemas agrícolas é fundamental, ainda que seja conservacionista, uma vez que esses sistemas não são auto-sustentáveis, pois há a exportação de elementos pelas partes comercializáveis das culturas e são inevitáveis as ocorrências de perdas naturais; assim, a melhoria dos atributos químicos do solo para o cultivo da cana dispõe, dentre alternativas, da aplicação de vinhaça, torta de filtro e fertilizantes (Silva \& Ribeiro, 1995; Canellas et al., 2003), para atender às expectativas de produtividade e à reposição dos nutrientes exportados pela cultura do sistema solo.

O objetivo deste trabalho foi avaliar as características agronômicas da cana-de-açúcar em função do sistema de plantio direto (SPD) comparativamente ao convencional (PC) com e sem a aplicação de adubo, em Campos dos Goytacazes, RJ.

\section{MATERIAL E MÉTODOS}

O experimento de campo foi conduzido no município de Campos dos Goytacazes (situado a $21^{\circ} 44^{\prime} 47^{\prime}$ de latitude Sul e $41^{\circ} 18$ ' 24” de longitude Oeste com altitude de $12 \mathrm{~m}$ ), na Região Norte do Estado do Rio de Janeiro, no período de 30 de março de 2004 a 01 julho de 2005. Os dados climáticos referentes ao período da condução do experimento, estão na Figura 1.

O experimento foi conduzido em Cambissolo Ta eutrófico argiloso, com boa drenagem, e textura argila-siltosa, em torno de 38, 52 e 10\% argila, silte e areia total, respectivamente. Durante cerca de 30 anos esta área foi cultivada com cana-de-açúcar e pelo menos nos últimos 10 anos foi cultivada sem aplicação de adubo no plantio e em cobertura na cana-soca, indicando solo com baixa fertilidade. A análise química do solo, anterior à instalação do experimento, evidenciou valores de $\mathrm{pH}\left(\mathrm{H}_{2} \mathrm{O}\right)=5,5$; $\mathrm{S}_{-} \mathrm{SO}_{4}=$ $17,8 \mathrm{mg} \mathrm{dm}^{-3} ; \mathrm{P}=41,8 \mathrm{mg} \mathrm{dm}^{-3} ; \mathrm{K}^{+}=0,34 \mathrm{cmol}_{\mathrm{C}} \mathrm{dm}^{-3}$; $\mathrm{Ca}^{++}=5,03 \mathrm{cmol}_{\mathrm{C}} \mathrm{dm}^{-3} ; \mathrm{Mg}^{++}=2,47 \mathrm{cmol}_{\mathrm{C}} \mathrm{dm}^{-3} ; \mathrm{Al}^{+++}=$ $0,22 \mathrm{cmol}_{\mathrm{C}} \mathrm{dm}^{-3} ; \mathrm{H}^{+}+\mathrm{Al}=4,31 \mathrm{cmol}_{\mathrm{C}} \mathrm{dm}^{-3} ; \mathrm{Na}^{+}=0,22$ $\mathrm{Cmol}_{\mathrm{C}} \mathrm{dm}^{-3} ; \mathrm{C}=19,4 \mathrm{~g} \mathrm{dm}^{-3} ;$ M.O. $=33,4 \mathrm{~g} \mathrm{dm}^{-3} ; \mathrm{Fe}=$ $127,0 \mathrm{mg} \mathrm{dm}^{-3} ; \mathrm{Cu}=3,2 \mathrm{mg} \mathrm{dm}^{-3} ; \mathrm{Zn}=3,9 \mathrm{mg} \mathrm{dm}^{-3} ; \mathrm{Mn}=$ $14,7 \mathrm{mg} \mathrm{dm}^{-3}$ e $\mathrm{B}=0,4 \mathrm{mg} \mathrm{dm}^{-3}$. A calagem foi realizada em novembro de 2003, com quatro meses de antecedência do plantio da cana, aplicando-se calcário calcítico com PRNT de $80 \%$, na dose de $0,75 \mathrm{t} \mathrm{ha}^{-1}$. Como melhorador 

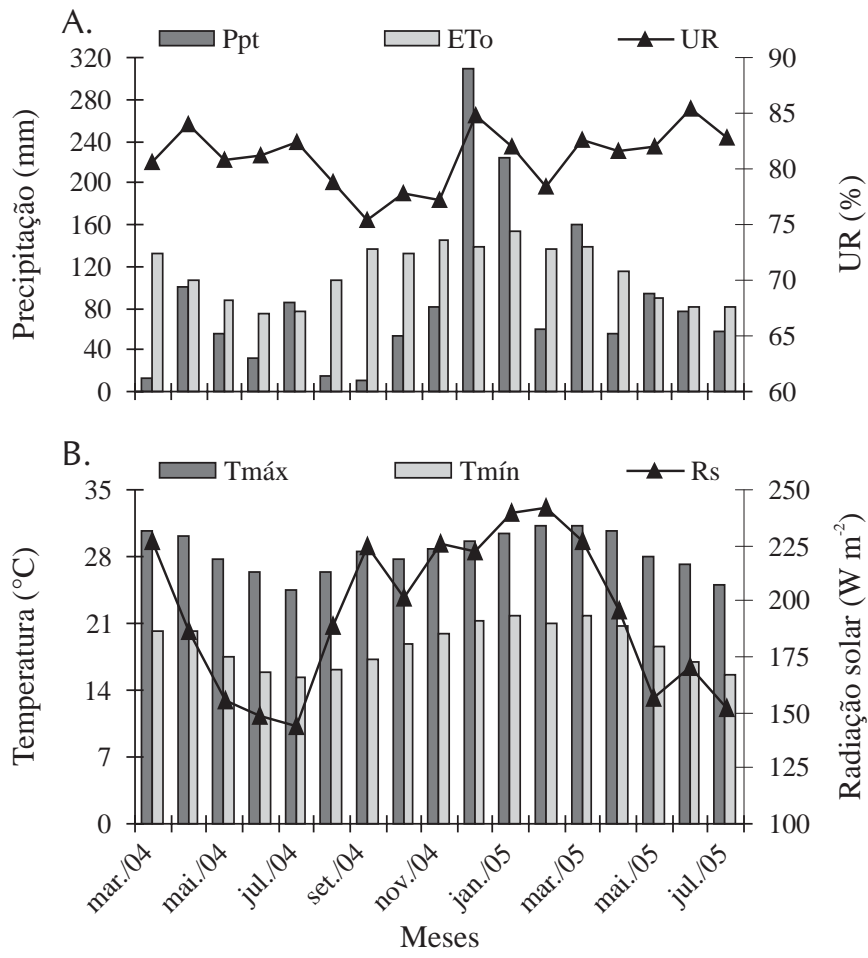

Figura 1. Dados climáticos durante o período de março de 2004 a julho de 2005. A) Precipitação total (Ppt), evapotranspiração de referência (ETo) e médias de umidade relativa (UR) e em B) médias de temperatura máxima (Tmáx), temperatura mínima (Tmín) e radiação solar (Rs). Fonte: Estação climatológica da UENF/PESAGRO, RJ

da fertilidade do solo se aplicou o gesso agrícola, tomando-se de base $30 \%$ da recomendação de calagem, o que resultou na dose de $0,23 \mathrm{t} \mathrm{ha}^{-1}$; posteriormente, foram cultivados os adubos verdes crotalária (Crotalaria juncea), feijão de porco (Canavalia ensifomis) e mucuna preta (Mucuna aterrima), objetivando a cobertura e proteção do solo, a fixação biológica de nitrogênio, a reciclagem de nutrientes e a formação de palhada para a implantação do sistema de plantio direto de cana-de-açúcar.

O delineamento experimental foi em blocos casualizados, com quatro repetições, em esquema fatorial $4 \times 2$, no qual foram avaliados quatro sistemas de cultivo para a cana com ou sem adubação: (I) - cana PC vegetação espontânea incorporada com adubação e (II) - idem I sem adubação; (III) cana SPD sobre feijão de porco com adubação e (IV) - idem III sem adubação; (V) - cana SPD sobre mucuna com adubação e (VI) - idem V sem adubação e (VII) - cana SPD sobre crotalária com adubação e (VIII) - idem VII sem adubação.

A parcela ou unidade experimental de $11 \mathrm{~m}$ de largura e $11 \mathrm{~m}$ de comprimento teve 8 linhas espaçadas 1,3 m para a cana-de-açúcar, totalizando $121 \mathrm{~m}^{2}$. A área total do experimento foi de $3.872 \mathrm{~m}^{2}$. Os blocos foram dispostos seguindo transversalmente o gradiente de argila do terreno determinado pela análise textural do solo, com uma faixa de $2 \mathrm{~m}$ separando os blocos. Foi utilizada, em cultivo de ano-e-meio, a variedade de cana SP80-1842, que apresenta boas produtividades agrícolas em planta e soca, sendo caracterizada pelo rápido crescimento vegetativo, boa brotação da soqueira, muito boa em teor de sacarose, não é comum a ocorrência de isoporização, é resistente a carvão e ferrugem, e susceptível a escaldadura e broca da cana-de-açúcar.

Nas parcelas da cana convencional, se preparou o solo com uma aração média e duas operações de gradagens, utilizando-se um trator da marca Ford 6630 acoplado ao arado de discos ou a grade niveladora. Em 30 de março de 2004 fez-se a sulcagem em todas as parcelas com auxílio de trator marca Ford 6630, acoplado a um sulcador de duas linhas e, posteriormente, o plantio manual da cana com e sem adubação na base, com sulcos de 0,4 m profundidade para o sistema de plantio direto e convencional. Foram aplicados, nos tratamentos com adubação, 444 e $133 \mathrm{~kg} \mathrm{ha}^{-1}$ de superfosfato simples e cloreto de potássio, respectivamente; a expectativa de produtividade era de $150 \mathrm{t} \mathrm{ha}^{-1}$, utilizando-se como base o Boletin 100 do IAC (Raij et al., 1996). Considerouse emergência da cana-de-açúcar a época em que aproximadamente 50\% dos brotos emergiram.

Para o manejo das plantas daninhas na cana-planta igual em todos os tratamentos aos 15 dias após o plantio (DAP), realizou-se a aplicação de herbicidas pré e pós-emergentes, diuron + hexazinona na dose de $2,0 \mathrm{~kg} \mathrm{ha}^{-1}$ do produto comercial e metano arseniato ácido monossódico (MSMA) na dose de 2,4 kg ha-1 do produto comercial, além do espalhante adesivo aquil fenol poliglicoléter na concentração de $2 \%$ do volume da calda, sendo de $200 \mathrm{~L} \mathrm{ha}^{-1}$ o volume de calda. A aplicação foi realizada no período da manhã, das 6 às $7 \mathrm{~h}$, para evitar a deriva causada pelo vento e perdas por evaporação devido a altas temperaturas. Não houve incidência de pragas e doenças na cultura em nível de causar danos econômicos ou experimentais. Irrigou-se somente quando extremamente necessário, utilizando-se o sistema de aspersão para a irrigação.

Para a análise foliar no mês de agosto/2004, foram coletados amostras foliares da cana-de-açúcar (cana-planta), da posição +3 , de plantas com quatro meses de idade. Cada amostra foi constituída de 10 folhas coletadas aleatoriamente, em uma área útil da unidade experimental de 9,1 m² (paralela à área útil para a determinação da produtividade). Das folhas amostradas foram utilizados, na análise, os 20 centímetros medianos, descartando-se a nervura central; essas amostras foram submetidas a secagem em estufa a $70^{\circ} \mathrm{C}$ com circulação forçada de ar durante 72 h e moídas em moinho tipo Wiley (com peneiras de 20 mesh). Utilizaram-se para determinação de P, K, Ca, Mg, S, Mn, Cu, Fe e Zn, amostras de 0,50 g do material vegetal moído e submetidas a digestão nítrico-perclórica (Jones et al., 1991; Malavolta, 1997). Para a determinação do N orgânico se usaram amostras de $0,10 \mathrm{~g}$ de material vegetal moído, que foram submetidas a digestão sulfúrica (Linder, 1944; Jones et al., 1991; Malavolta, 1997). No extrato se dosou o N orgânico, utilizando-se o reagente de Nessler (Jackson, 1965).

Dados de produtividade foram coletados quando a cana atingiu o ponto de maturação ideal, cortando-se as duas linhas centrais manualmente, sem queimada prévia, ou seja, a cana foi colhida crua na área útil central da parcela de 18,2 $\mathrm{m}^{2}$. Pesaram-se os colmos da cana colhida com auxílio de uma balança da marca Caudura, modelo F3 e um galão de massa previamente tarada. Dez colmos colhidos da área 
útil foram utilizados para determinar o diâmetro médio, medindo-se o terço médio do colmo. Na ocasião da colheita o número de colmos foi contado e determinado o número de colmos por hectare; posteriormente foram coletados, aleatoriamente, dez colmos dos já pesados. Formou-se um feixe, que foi devidamente identificado e encaminhado ao laboratório de usina de açúcar com destilaria anexa, para determinar brix, leitura sacarimétrica $(\mathrm{L})$ e peso do bagaço úmido (PBU). Para calcular a ATR se utilizaram as equações propostas pela organização de plantadores de cana da Região Centro-Sul do Brasil (OPLANA, 2005).

Os resultados de teores foliares de nutrientes, de características agroindustriais, de número, diâmetro e produtividade de colmos da cana-de-açúcar, foram analisados estatisticamente. Fez-se a análise de variância preliminar (Teste F) e o desdobramento dos graus de liberdade de tratamentos. Nos casos em que na análise de variância o " $F_{\text {cal }}$ foi significativo, ou seja, rejeitou-se a hipótese de nulidade para cada fator isolado, as médias dentro de cada sistema de manejo foram comparadas pelo teste de Tukey em nível de 5\% de probabilidade, porém quando do estudo do fator adubação (cana adubada ou não adubada), por serem duas médias, aplicou-se o teste F em nível de 5\% de probabilidade (Ferreira, 2000; Ribeiro Júnior, 2001).

\section{RESULTADOS E DISCUSSÃO}

Os teores de nitrogênio foliar da cana SPD sobre feijão de porco e mucuna, se apresentaram, em média, 11 e $26 \%$ superiores ao obtido na cana SPD sobre crotalária e cana convencional, respectivamente (Tabela 1); portanto, o feijão de porco e a mucuna se mostraram mais eficientes na disponibilização de $\mathrm{N}$ para a cana-de-açúcar. O plantio direto de cana sobre feijão de porco, mucuna e crotalária proporcionou teores foliares de N 29, 24 e 14\% superiores ao proporcionado pelo convencional sobre vegetação espontânea; desta forma, apenas os teores de $\mathrm{N}$ nas folhas da cana em SPD sobre as leguminosas estão dentro da faixa adequada de 19 a $21 \mathrm{~g} \mathrm{~kg}^{-1}$ proposta por Malavolta (1997) porém todos os teores de $\mathrm{N}$ foliar da cana obtidos neste trabalho foram superiores ao proposto por Reis Jr. \& de canaviais de alta produtividade (eH 75 t ha $^{-1}$ ) no município de Campos dos Goytacazes, RJ, e aos teores adequados propostos por Reis Jr. (1999); no entanto, a alta produtividade dita por Reis Jr. \& Monnerat (2002) é inferior à menor obtida neste trabalho (Tabela 4). Com respeito à cana com e sem adubo, não se apresentaram teores foliares de $\mathrm{N}$ na matéria seca diferentes entre si significativamente, sendo o esperado, pois não se aplicou nenhuma fonte nitrogenada de adubo.

Para os teores foliares de P, Ca e Fe da cana não houve diferenças significativas entre os sistemas de manejo do solo nem para a cana com e sem adubo (Tabelas 1 e 2) em virtude provavelmente, do nível de $\mathrm{P}\left(41,8 \mathrm{~g} \mathrm{dm}^{-3}\right)$, Ca $\left(5,03 \mathrm{cmol}_{\mathrm{C}} \mathrm{dm}^{-3}\right)$ e Fe $\left(127,0 \mathrm{mg} \mathrm{dm}^{-3}\right)$ do solo que já eram considerados altos e adequados (Malavolta, 1997). Os teores foliares de $\mathrm{P}$ obtidos estão bem acima da faixa adequada de 2,0 a 2,4 $\mathrm{g} \mathrm{kg}^{-1}$ (Malavolta, 1997) e de 1,91 a
Tabela 1. Teores de macronutrientes na folha +3 da cana-planta variedade SP80-1842 com quatro meses de idade, em função do sistema de plantio direto e convencional com e sem adubação em Campos dos Goytacazes, RJ

\begin{tabular}{|c|c|c|c|}
\hline \multirow{2}{*}{$\begin{array}{c}\text { Plantas de cobertura e sistema } \\
\text { de manejo (SMS) }\end{array}$} & \multicolumn{2}{|c|}{$\begin{array}{l}\text { Adubação no plantio } \\
\text { (ADU) }\end{array}$} & \multirow[t]{2}{*}{ Médias } \\
\hline & $00-20-60$ & $00-00-00$ & \\
\hline & \multicolumn{3}{|c|}{ Nitrogênio $\left(\mathrm{g} \mathrm{kg}^{-1}\right)$} \\
\hline Crotalária juncea - cana PD & 18,4 & 18,7 & $18,6 b^{1}$ \\
\hline Feijão de porco - cana PD & 20,7 & 21,3 & $21,0 \mathrm{a}$ \\
\hline Mucuna preta - cana PD & 20,2 & 20,2 & $20,2 \mathrm{a}$ \\
\hline Veg. espontânea - cana convencional & 16,4 & 16,2 & $16,3 \mathrm{c}$ \\
\hline Médias & $19,0 \mathrm{~A}$ & $19,0 \mathrm{~A}$ & 19,0 \\
\hline \multirow[t]{2}{*}{ CV (\%) } & & 4 & \\
\hline & \multicolumn{3}{|c|}{ Fósforo $\left(\mathrm{g} \mathrm{kg}^{-1}\right)$} \\
\hline Crotalária juncea - cana PD & 5,7 & 5,7 & $5,7 \mathrm{a}$ \\
\hline Feijão de porco - cana PD & 5,7 & 5,6 & $5,7 \mathrm{a}$ \\
\hline Mucuna preta - cana PD & 6,3 & 5,5 & $5,9 \mathrm{a}$ \\
\hline Veg. espontânea - cana convencional & 5,6 & 5,6 & $5,6 \mathrm{a}$ \\
\hline Médias & $5,8 \mathrm{~A}$ & $5,6 \mathrm{~A}$ & 5,7 \\
\hline \multirow[t]{2}{*}{ CV (\%) } & & 9 & \\
\hline & \multicolumn{3}{|c|}{ Potássio $\left(\mathrm{g} \mathrm{kg}^{-1}\right)$} \\
\hline Crotalária juncea - cana PD & 12,9 & 12,7 & $12,8 \mathrm{a}$ \\
\hline Feijão de porco - cana PD & 12,6 & 10,7 & $11,6 \mathrm{a}$ \\
\hline Mucuna preta - cana PD & 13,3 & 11,5 & $12,4 \mathrm{a}$ \\
\hline Veg. espontânea - cana convencional & 9,1 & 8,0 & $8,6 \mathrm{~b}$ \\
\hline Médias & $12,0 \mathrm{~A}$ & $10,7 \mathrm{~B}$ & 11,3 \\
\hline \multirow[t]{2}{*}{ CV (\%) } & & 13 & \\
\hline & \multicolumn{3}{|c|}{ Cálcio $\left(\mathrm{g} \mathrm{kg}^{-1}\right)$} \\
\hline Crotalária juncea - cana PD & 4,4 & 4,1 & $4,3 \mathrm{a}$ \\
\hline Feijão de porco - cana PD & 4,4 & 4,7 & $4,5 \mathrm{a}$ \\
\hline Mucuna preta - cana PD & 3,7 & 4,0 & $3,9 \mathrm{a}$ \\
\hline Veg. espontânea - cana convencional & 4,4 & 4,8 & $4,6 \mathrm{a}$ \\
\hline Médias & $4,2 \mathrm{~A}$ & $4,4 \mathrm{~A}$ & 4,3 \\
\hline \multirow[t]{2}{*}{ CV (\%) } & & 12 & \\
\hline & \multicolumn{3}{|c|}{ Magnésio $\left(\mathrm{g} \mathrm{kg}^{-1}\right)$} \\
\hline Crotalária juncea - cana PD & 2,4 & 2,8 & $2,6 \mathrm{~b}$ \\
\hline Feijão de porco - cana PD & 2,7 & 3,1 & $2,9 \mathrm{a}$ \\
\hline Mucuna preta - cana PD & 2,4 & 2,9 & $2,6 \mathrm{~b}$ \\
\hline Veg. espontânea - cana convencional & 2,5 & 2,6 & $2,5 \mathrm{~b}$ \\
\hline Médias & $2,5 \mathrm{~B}$ & $2,9 \mathrm{~A}$ & 2,7 \\
\hline \multirow[t]{2}{*}{ CV (\%) } & & 6 & \\
\hline & \multicolumn{3}{|c|}{ Enxofre $\left(\mathrm{g} \mathrm{kg}^{-1}\right)$} \\
\hline Crotalária juncea - cana PD & 3,8 & 4,1 & $4,0 \mathrm{~b}$ \\
\hline Feijão de porco - cana PD & 4,2 & 4,2 & $4,2 a b$ \\
\hline Mucuna preta - cana PD & 4,3 & 4,3 & $4,3 \mathrm{a}$ \\
\hline Veg. espontânea - cana convencional & 4,2 & 4,3 & $4,3 \mathrm{a}$ \\
\hline Médias & $4,1 \mathrm{~A}$ & $4,2 \mathrm{~A}$ & 4,2 \\
\hline CV (\%) & & 5 & \\
\hline
\end{tabular}

1/ Médias na linha, seguidas de letras maiúsculas diferentes, são diferentes pelo teste $\mathrm{F}$ em níve de $5 \%$ de probabilidade, e na coluna seguidas de letras minúsculas diferentes, são diferentes pelo teste de Tukey em nível de $5 \%$ de probabilidade

2,12 $\mathrm{g} \mathrm{kg}^{-1}$ sugeridos por autores que desenvolveram pesquisas em Campos dos Goytacazes (Reis Jr., 1999; Reis Jr. \& Monnerat, 2002), para canaviais de alta produtividade. Desta maneira, fica evidenciado que o P não foi um elemento limitante à produtividade da cana. Os teores foliares de $\mathrm{Ca}$ e Fe da cana se encontravam abaixo das respectivas faixas de 8 a $10 \mathrm{~g} \mathrm{~kg}^{-1}$ e 200 a $500 \mathrm{mg} \mathrm{kg}^{-1}$ (Malavolta, 1997), sendo que o teor de Ca se encontrava acima de 2,99 
a 3,44 g kg-1 $^{-1}$ (Reis Jr., 1999; Reis Jr. \& Monnerat, 2002) sugeridos por esses autores locais, para canaviais de alta produtividade; assim, ao se utilizar critérios estabelecidos em Campos dos Goytacazes para interpretar a análise química das amostras, verifica-se que o teor foliar de Ca está alto e adequado, mas, se utilizar outra literatura, os teores de Ca e Fe nas folhas da cana serão caracterizados limitantes da produtividade, ocasião pela qual, talvez seja necessário estabelecer critérios de avaliação nutricional com base nas condições edafoclimáticas locais.

Os teores médios de K e Zn foliar da cana em SPD sobre as leguminosas se apresentaram, respectivamente, 43 e 17\% superiores à cana convencional com vegetação espontânea incorporada (Tabelas 1 e 2). Em média o teor de $\mathrm{K}$ foi de $12,3 \mathrm{~g} \mathrm{~kg}^{-1}$ nas folhas de cana em SPD considerado, portanto, dentro da faixa adequada de 11 a $13 \mathrm{~g} \mathrm{~kg}^{-1}$ (Malavolta, 1997) e de cana de alta produtividade (Reis Jr., 1999; Reis Jr. \& Monnerat, 2002) porém na cana convencional ocorreu o inverso, isto é, o teor de $\mathrm{K}$ estava $22 \%$ abaixo do limite inferior da faixa adequada (Malavolta, 1997). Desta maneira, o K foi possivelmente um elemento limitante da produti-

Tabela 2. Teores de micronutrientes na folha +3 da cana-planta variedade SP80-1842 com quatro meses de idade, em função do sistema de plantio direto e convencional com e sem adubação em Campos dos Goytacazes, RJ

\begin{tabular}{|c|c|c|c|}
\hline \multirow{2}{*}{$\begin{array}{c}\text { Plantas de cobertura e sistema } \\
\text { de manejo (SMS) }\end{array}$} & \multicolumn{2}{|c|}{$\begin{array}{l}\text { Adubação no plantio } \\
\text { (ADU) }\end{array}$} & \multirow[t]{2}{*}{ Médias } \\
\hline & $00-20-60$ & $00-00-00$ & \\
\hline & \multicolumn{3}{|c|}{ Manganês $\left(\mathrm{mg} \mathrm{kg}^{-1}\right)$} \\
\hline Crotalária juncea - cana PD & 113,7 & 110,3 & $112,0 \mathrm{~b}^{1}$ \\
\hline Feijão de porco - cana PD & 114,7 & 95,7 & 105,2 b \\
\hline Mucuna preta - cana PD & 109,9 & 108,5 & $109,2 \mathrm{~b}$ \\
\hline Veg. espontânea - cana convencional & 148,3 & 157,7 & $153,0 \mathrm{a}$ \\
\hline Médias & $121,7 \mathrm{~A}$ & $118,0 \mathrm{~A}$ & 119,8 \\
\hline \multirow[t]{2}{*}{ CV $(\%)$} & & 14 & \\
\hline & \multicolumn{3}{|c|}{ Zinco $\left(\mathrm{mg} \mathrm{kg}^{-1}\right)$} \\
\hline Crotalária juncea - cana PD & 14,4 & 15,5 & $15,0 \mathrm{a}$ \\
\hline Feijão de porco - cana PD & 16,0 & 16,5 & $16,3 \mathrm{a}$ \\
\hline Mucuna preta - cana PD & 14,7 & 16,4 & $15,6 \mathrm{a}$ \\
\hline Veg. espontânea - cana convencional & 13,3 & 13,4 & $13,4 \mathrm{~b}$ \\
\hline Médias & $14,6 \mathrm{~B}$ & $15,5 \mathrm{~A}$ & 15,0 \\
\hline \multirow[t]{2}{*}{ CV $(\%)$} & & 6 & \\
\hline & \multicolumn{3}{|c|}{ Ferro $\left(\mathrm{mg} \mathrm{kg}^{-1}\right)$} \\
\hline Crotalária juncea - cana PD & 84,6 & 79,1 & $81,8 \mathrm{a}$ \\
\hline Feijão de porco - cana PD & 90,0 & 101,7 & 95,9 a \\
\hline Mucuna preta - cana PD & 82,6 & 88,5 & $85,5 \mathrm{a}$ \\
\hline Veg. espontânea - cana convencional & 100,3 & 100,1 & $100,2 \mathrm{a}$ \\
\hline Médias & $89,4 \mathrm{~A}$ & $92,4 \mathrm{~A}$ & 90,9 \\
\hline \multirow[t]{2}{*}{ CV (\%) } & & 15 & \\
\hline & \multicolumn{3}{|c|}{ Cobre $\left(\mathrm{mg} \mathrm{kg}^{-1}\right)$} \\
\hline Crotalária juncea - cana PD & 4,2 & 4,3 & $4,3 \mathrm{~b}$ \\
\hline Feijão de porco - cana PD & 5,5 & 5,5 & $5,5 \mathrm{a}$ \\
\hline Mucuna preta - cana PD & 5,0 & 5,0 & $5,0 \mathrm{a}$ \\
\hline Veg. espontânea - cana convencional & 3,9 & 4,3 & $4,1 \mathrm{~b}$ \\
\hline Médias & $4,7 \mathrm{~A}$ & $4,8 \mathrm{~A}$ & 4,7 \\
\hline CV (\%) & & 9 & \\
\hline
\end{tabular}

1/ Médias na linha, seguidas de letras maiúsculas diferentes, são diferentes pelo teste $\mathrm{F}$ em nível de $5 \%$ de probabilidade, e na coluna seguidas de letras minúsculas diferentes, são diferentes pelo teste de Tukey em nível de $5 \%$ de probabilidade vidade da cana convencional; em média, a cana adubada apresentou-se com teor de $\mathrm{K}$ foliar dentro da faixa adequada e de cana de alta produtividade (Malavolta, 1997; Reis Jr., 1999; Reis Jr. \& Monnerat, 2002), evidenciando o efeito positivo e necessário da adubação potássica, enquanto a cana não adubada obteve teor de $\mathrm{K}$ aproximadamente 3 e 11\% inferior ao limite inferior da faixa adequada de Malavolta (1997) e da cana com adubo, respectivamente.

A faixa adequada de teor de $\mathrm{Zn}$, é de 25 a $30 \mathrm{mg} \mathrm{kg}^{-1}$ de acordo com Malavolta (1997), mas os maiores teores foliares apresentados pela cana foram no SPD sobre as leguminosas, em média de $15,6 \mathrm{mg} \mathrm{kg}^{-1}$, se encontrando, porém, abaixo da faixa adequada. Por outro lado, o teor médio de Zn obtido pela cana SPD foi $9 \%$ superior ao segerido por Reis Jr. \& Monnerat (2002) de 14,3 $\mathrm{mg} \mathrm{kg}^{-1}$ de cana de alta produtividade; todavia, o teor foliar de $\mathrm{Zn}$ da cana adubada foi aproximadamente $6 \%$ inferior da cana não adubada (Tabela 2); este menor teor de Zn na cana adubada possivelmente seja explicado pela presença do $\mathrm{P}$, pois alto nível de fósforo no meio solo (neste caso favorecido pela adubação fosfatada), causou a diminuição na absorção de Zn, que poderia ter provocado sintomas de carência, o que se deve a várias causas: o P insolubiliza o Zn na superfície das raízes diminuindo sua absorção, o $\mathrm{P}$ insolubiliza o Zn no xilema diminuindo o transporte para a parte aérea, de acordo com Malavolta (1997).

A cana sobre crotalária, mucuna e vegetação espontânea, apresentou, em média teor de Mg foliar que não diferiu entre si, mas foi aproximadamente $12 \%$ inferior a cana SPD sobre feijão de porco (Tabela 1). Os teores foliares de Mg na cana se apresentavam, independente do tratamento a que foi submetida dentro da faixa adequada, de 2 a $3 \mathrm{~g} \mathrm{~kg}^{-1}$ proposto por Malavolta (1997) e de cana de alta produtividade sugerido por Reis Jr. (1999) e Reis Jr. \& Monnerat (2002); já a cana adubada se apresentou com teor de Mg foliar aproximadamente $14 \%$ inferior ao da cana não adubada, em razão das plantas absorverem o magnésio como $\mathrm{Mg}^{+2}$ e altas concentrações de $\mathrm{Ca}$, principalmente de $\mathrm{K}^{+}$no meio solo (neste caso, favorecido pela adubação potássica), o que, possivelmente inibiu, de forma competitiva a absorção, embora pudessem causar deficiência. É provável que a alta concentração de $\mathrm{K}$ proporcionada pela adubação potássica tenha causado, neste caso, efeito antagônico à absorção de Mg, reduzindo o teor foliar deste último elemento, significativamente na cana adubada.

A cana SPD sobre feijão de porco obteve teor de S nas folhas, que não diferiu da cana SPD sobre crotalária, mucuna e vegetação espontânea (Tabela 1). Em média, a cana SPD sobre crotalária se apresentou com teor de S foliar 7\% inferior ao da cana sobre mucuna e vegetação espontânea. Não houve diferença significativa entre os teores foliares de S apresentados pela cana adubada e pela não adubada; todavia, os teores foliares apresentados pela cana sob os diferentes tratamentos, se encontravam acima da faixa adequada de 2,5 a 3,0 (Malavolta, 1997) e do teor médio de $\mathrm{S}$ foliar de cana de alta produtividade, sugerido por Reis Jr. \& Monnerat (2002).

A cana convencional com vegetação espontânea 
incorporada apresentou-se com o teor de Mn foliar $41 \%$ maior que o teor médio apresentado pela cana SPD sobre as leguminosas, que não diferiram entre si significativamente (Tabela 2). A cana adubada não obteve maior teor de $\mathrm{Mn}$ foliar em relação à não adubada. Os teores foliares de Mn obtidos pela cana nos diferentes tratamentos a que foram submetidos ficaram dentro da faixa de 100 a $250 \mathrm{mg} \mathrm{kg}^{-1}$, considerada adequada (Malavolta, 1997), e acima do teor médio de 74,4 $\mathrm{mg} \mathrm{kg}^{-1}$ para cana de alta produtividade (Reis Jr. \& Monnerat, 2002).

A cana SPD sobre feijão de porco e mucuna não diferiu em teor de $\mathrm{Cu}$ nas folhas (Tabela 2); entretanto, foi $25 \%$ superior à média de cana sobre crotalária e convencional com vegetação espontânea incorporada. Para o teor de $\mathrm{Cu}$ nas folhas não houve diferença da cana adubada em relação à não adubada, mas, todos os teores de $\mathrm{Cu}$ apresentados nas folhas da cana deste experimento, independente do tratamento recebido, foram abaixo da faixa de 8 a $10 \mathrm{mg} \mathrm{kg}^{-1}$ (Malavolta, 1997). De acordo com (Reis Jr. \& Monnerat, 2002), a cana SPD, feijão de porco e mucuna, apresentaram, em média, teores foliares de $\mathrm{Cu}$ superiores ao sugerido para cana de alta produtividade.

Ao se levar em consideração os critérios estabelecidos por Malavolta (1997), nitrogênio e potássio na cana convencional, seriam os nutrientes que, possivelmente, estariam limitando a produção da cana-de-açúcar. O potássio tem papel reconhecido na síntese de açúcares e é o nutriente mais exportado pela cultura da cana-de-açúcar, enquanto o nitrogênio apresenta característica de proporcionar maior vegetação e perfilhamento da cana. Outros nutrientes como Ca, Fe, Zn e $\mathrm{Cu}$, seriam os que, provavelmente, estariam limitando a produção da cana, independente dos tratamentos aplicados. O cobre e o zinco são os micronutrientes mais limitantes para a cultura da cana-de-açúcar no Brasil (Orlando Filho et al., 1994), e as aduções nitrogenadas e potássicas podem contribuir para o surgimento da limitação por parte desses nutrientes. A deficiência de cálcio pode causar retardamento no crescimento da planta e redução no sistema radicular, enquanto o ferro causa clorose internerval. Na região CentroSul do Brasil, a deficiência pode ocorrer na fase inicial da brotação das soqueiras, porém é de ocorrência efêmera, sem necessitar de correção (Orlando Filho et al., 1994). Quando da ausência da adubação, o potássio foi o nutriente limitante da produção da cana-de-açúcar; todavia, pode-se constatar que este elemento poderá limitar ainda mais a produtividade, quando da não utilização do SPD empregando-se os adubos verdes.

Para as características agroindustriais brix, pureza do caldo, ATR e APV, não houve efeito significativo dos tratamentos aplicados à cana-de-açúcar (Tabela 3). Mas, quanto à fibra da cana, notou-se que a cana convencional com vegetação espontânea incorporada apresentou 7\% a mais fibrosa que a cana SPD sobre as leguminosas.

Devido, provavelmente, ao menor teor de potássio apresentado pela cana convencional (Tabela 1 ), pois o $\mathrm{K}$ tem papel reconhecido na síntese de açúcares; portanto, quando há menor acúmulo de açúcar, o aumento de fibra na cana é favorecida.
Tabela 3. Características agroindustriais Brix, Fibra da cana, Pol da cana, açúcares teoricamente recuperáveis (ATR) e álcool provável (APV) de cana-planta variedade SP80-1842, em função do sistema de plantio direto e convencional com e sem adubação em Campos dos Goytacazes, RJ

\begin{tabular}{|c|c|c|c|}
\hline \multirow{2}{*}{$\begin{array}{l}\text { Plantas de cobertura e sistema } \\
\text { de manejo (SMS) }\end{array}$} & \multicolumn{2}{|c|}{$\begin{array}{l}\text { Adubaçãa no plantio } \\
\text { (ADU) }\end{array}$} & \multirow[t]{2}{*}{ Médias } \\
\hline & $00-20-60$ & $00-00-00$ & \\
\hline & \multicolumn{3}{|c|}{ Brix $\left(^{\circ}\right)$} \\
\hline Crotalária juncea - cana PD & 17,8 & 17,4 & $17,6 \mathrm{a}^{1}$ \\
\hline Feijão de porco - cana PD & 17,6 & 17,7 & $17,6 \mathrm{a}$ \\
\hline Mucuna preta - cana PD & 17,7 & 18,0 & $17,8 \mathrm{a}$ \\
\hline Veg. espontânea - cana convencional & 18,0 & 17,6 & $17,8 \mathrm{a}$ \\
\hline Médias & $17,8 \mathrm{~A}$ & $17,6 \mathrm{~A}$ & 17,7 \\
\hline \multirow[t]{2}{*}{ CV (\%) } & & 6 & \\
\hline & \multicolumn{3}{|c|}{ Pureza do caldo (\%) } \\
\hline Crotalária juncea - cana PD & 88,5 & 87,2 & $87,8 \mathrm{a}$ \\
\hline Feijão de porco - cana PD & 91,3 & 91,0 & $91,1 \mathrm{a}$ \\
\hline Mucuna preta - cana PD & 92,9 & 91,4 & $92,2 \mathrm{a}$ \\
\hline Veg. espontânea - cana convencional & 92,0 & 90,6 & 91,3 a \\
\hline Médias & $91,2 \mathrm{~A}$ & $90,1 \mathrm{~A}$ & 90,6 \\
\hline \multirow[t]{2}{*}{ CV (\%) } & & 4 & \\
\hline & \multicolumn{3}{|c|}{ Fibra da cana (\%) } \\
\hline Crotalária juncea - cana PD & 12,1 & 11,6 & $11,8 \mathrm{~b}$ \\
\hline Feijão de porco - cana PD & 11,9 & 11,8 & $11,9 \mathrm{~b}$ \\
\hline Mucuna preta - cana PD & 12,1 & 12,1 & $12,1 \mathrm{~b}$ \\
\hline Veg. espontânea - cana convencional & 12,6 & 13,0 & $12,8 \mathrm{a}$ \\
\hline Médias & $12,2 \mathrm{~A}$ & $12,1 \mathrm{~A}$ & 12,1 \\
\hline \multirow[t]{2}{*}{ CV (\%) } & & 4 & \\
\hline & \multicolumn{3}{|c|}{ Pol da cana (\%) } \\
\hline Crotalária juncea - cana PD & 13,3 & 12,9 & $13,1 \mathrm{a}$ \\
\hline Feijão de porco - cana PD & 13,6 & 13,7 & $13,6 \mathrm{a}$ \\
\hline Mucuna preta - cana PD & 13,9 & 13,9 & $13,9 \mathrm{a}$ \\
\hline Veg. espontânea - cana convencional & 13,9 & 13,2 & $13,6 \mathrm{a}$ \\
\hline Médias & $13,7 \mathrm{~A}$ & $13,4 \mathrm{~A}$ & 13,5 \\
\hline \multirow[t]{2}{*}{ CV (\%) } & & 6 & \\
\hline & \multicolumn{3}{|c|}{ ATR $\left(\mathrm{kg} \mathrm{ton}^{-1}\right)$} \\
\hline Crotalária juncea - cana PD & 128,8 & 124,8 & $126,8 \mathrm{a}$ \\
\hline Feijão de porco - cana PD & 130,4 & 131,1 & $130,7 \mathrm{a}$ \\
\hline Mucuna preta - cana PD & 132,6 & 133,0 & $132,8 \mathrm{a}$ \\
\hline Veg. espontânea - cana convencional & 132,9 & 127,2 & $130,1 \mathrm{a}$ \\
\hline Médias & $131,2 \mathrm{~A}$ & $129,0 \mathrm{~A}$ & 130,1 \\
\hline \multirow[t]{2}{*}{ CV (\%) } & & 6 & \\
\hline & \multicolumn{3}{|c|}{ APV $\left(\mathrm{Lton}^{-1}\right)$} \\
\hline Crotalária juncea - cana PD & 78,9 & 76,4 & $77,6 \mathrm{a}$ \\
\hline Feijão de porco - cana PD & 79,9 & 80,3 & $80,1 \mathrm{a}$ \\
\hline Mucuna preta - cana PD & 81,3 & 81,5 & $81,4 \mathrm{a}$ \\
\hline Veg. espontânea - cana convencional & 81,4 & 77,9 & $79,7 \mathrm{a}$ \\
\hline Médias & $80,4 \mathrm{~A}$ & $79,0 \mathrm{~A}$ & 79,7 \\
\hline CV (\%) & & 6 & \\
\hline
\end{tabular}

1/ Médias na linha seguidas de letras maiúsculas diferentes, são diferentes pelo teste $\mathrm{F}$ em nível de $5 \%$ de probabilidade, e na coluna seguidas de letras minúsculas diferentes, são diferentes pelo teste de Tukey em nível de $5 \%$ de probabilidade

A produtividade média da cana em SPD sobre as leguminosas foi de $135.863 \mathrm{~kg} \mathrm{ha}^{-1}$, sendo $37 \%$ superior à da cana convencional com vegetação espontânea incorporada (Tabela 4).

O mesmo ocorreu para número e diâmetro de colmos que, respectivamente, foram 27 e 32\% superiores na cana SPD em relação à convencional. Não houve diferença significativa de produtividade, de número e diâmetro de col- 
Tabela 4. Número de colmos por hectare, diâmetro de colmos e produtividade da cana-planta variedade SP80-1842, em função do sistema de plantio direto e convencional com e sem adubação em Campos dos Goytacazes, RJ

\begin{tabular}{|c|c|c|c|}
\hline \multirow{2}{*}{$\begin{array}{c}\text { Plantas de cobertura e sistema } \\
\text { de manejo (SMS) }\end{array}$} & \multicolumn{2}{|c|}{$\begin{array}{l}\text { Adubação no plantio } \\
\text { (ADU) }\end{array}$} & \multirow[t]{2}{*}{ Médias } \\
\hline & $00-20-60$ & $00-00-00$ & \\
\hline & \multicolumn{3}{|c|}{ Número de colmos (mil ha-1) } \\
\hline Crotalária juncea - cana PD & 78,0 & 79,3 & $78,6 \mathrm{a}^{1}$ \\
\hline Feijão de porco - cana PD & 72,7 & 68,8 & $70,7 \mathrm{a}$ \\
\hline Mucuna preta - cana PD & 75,0 & 75,3 & $75,1 \mathrm{a}$ \\
\hline Veg. espontânea - cana convencional & 61,5 & 56,6 & $59,1 \mathrm{~b}$ \\
\hline Médias & $71,8 \mathrm{~A}$ & $70,0 \mathrm{~A}$ & 70,9 \\
\hline \multirow[t]{2}{*}{ CV (\%) } & & 10 & \\
\hline & \multicolumn{3}{|c|}{ Diâmetro de colmos (cm) } \\
\hline Crotalária juncea - cana PD & 2,8 & 2,8 & $2,8 \mathrm{a}$ \\
\hline Feijão de porco - cana PD & 3,0 & 3,0 & $3,0 \mathrm{a}$ \\
\hline Mucuna preta - cana PD & 3,0 & 2,8 & $2,9 \mathrm{a}$ \\
\hline Veg. espontânea - cana convencional & 2,2 & 2,2 & $2,2 \mathrm{~b}$ \\
\hline Médias & $2,7 \mathrm{~A}$ & $2,7 \mathrm{~A}$ & 2,7 \\
\hline \multirow[t]{2}{*}{ CV $(\%)$} & \multicolumn{3}{|c|}{4} \\
\hline & \multicolumn{3}{|c|}{ Produtividade $\left(\mathrm{kg} \mathrm{ha}^{-1}\right)$} \\
\hline Crotalária juncea - cana PD & 135.385 & 128.434 & $131.909 \mathrm{a}$ \\
\hline Feijão de porco - cana PD & 145.357 & 137.198 & $141.278 \mathrm{a}$ \\
\hline Mucuna preta - cana PD & 135.611 & 133.194 & $134.403 \mathrm{a}$ \\
\hline Veg. espontânea - cana convencional & 112.342 & 85.673 & 99.008 b \\
\hline Médias & $132.174 \mathrm{~A}$ & $121.125 \mathrm{~B}$ & 126.650 \\
\hline CV (\%) & & 8 & \\
\hline
\end{tabular}

1/ Médias na linha, seguidas de letras maiúsculas diferentes, são diferentes pelo teste $\mathrm{F}$ em nível de $5 \%$ de probabilidade, e na coluna seguidas de letras minúsculas diferentes, são diferentes pelo teste de Tukey em nível de $5 \%$ de probabilidade

mos de cana SPD entre as diferentes leguminosas utilizadas neste trabalho, apesar da cana SPD sobre feijão de porco se apresentar com a maior produtividade absoluta (141.278 $\left.\mathrm{kg} \mathrm{ha}^{-1}\right)$.

A maior produtividade da cana SPD sobre as leguminosas, quando comparada com a cana convencional, se deve a vários fatores, como: maiores teores foliares de nitrogênio e potássio e, também, ao maior número e diâmetro de colmos obtidos na cana-de-açúcar cultivada em SPD sobre adubos verdes; esses resultados corroboram com Dalben et al. (1983) os quais, avaliando a produtividade da cana-planta variedade SP70-1143 em SPD, ainda sem adubação verde, constataram $11 \%$ de aumento de produtividade em relação à cana convencional.

Como já esperado, a cana-de-açúcar adubada apresentouse com produtividade $9 \%$ superior à da cana não adubada (Tabela 4). Vale ressaltar que, apesar de não apresentar diferenças significativas na interação sistema de manejo versus adubação, em termos absolutos a produtividade média da cana SPD sobre as leguminosas sem adubo foi $4 \%$ menor do que com aplicação de adubo; já a cana plantio convencional adubada apresentou queda de $24 \%$ quando não foi adubada, evidenciando que o decréscimo de produtividade devido à ausência de adubação foi agravado quando não se empregou o SPD com a adubação verde.

\section{CONCLUSÕES}

1. O sistema de plantio direto da cana-de-açúcar sobre leguminosas proporciona maiores teores foliares de $\mathrm{N}$ e $\mathrm{K}$ na cana do que o plantio convencional de cana com vegetação espontânea incorporada.

2. O feijão de porco e a mucuna preta proporcionam, em média, 26\% a mais de $\mathrm{N}$ para a cana sistema de plantio direto quando comparado com a cana plantio convencional.

3. A cana em sistema de plantio direto sobre leguminosas apresenta teores de K nas folhas $43 \%$ superiores à cana em plantio convencional.

4. A diagnose nutricional indica $\mathrm{N}$ e $\mathrm{K}$ como os principais nutrientes limitantes da produtividade da cana em plantio convencional, enquanto $\mathrm{Ca}, \mathrm{Fe}, \mathrm{Zn}$ e $\mathrm{Cu}$ se apresentam limitante, independente do sistema de manejo. O K é o principal nutriente limitante da produtividade da cana não adubada.

5. A cana-de-açúcar em sistema de plantio direto se apresenta 27, 32 e 37\% superior em número, diâmetro e produtividade de colmos, em relação à cana plantio convencional.

6. A cana-de-açúcar em sistema de plantio direto sobre leguminosas é mais produtiva do que em plantio convencional e garante maior preservação do ambiente devido à colheita da cana-crua, sem queimada.

\section{AGRADECIMENTOS}

À UENF/FAPERJ, pelo apoio financeiro; ao Grupo Queiroz Galvão e aos funcionários da Fazenda Abadia, pelo empréstimo da área com fins à realização da pesquisa, tratores, máquinas e implementos e por todo o apoio operacional.

\section{LITERATURA CITADA}

Amado, T. J. C.; Bayer, C.; Eltz, F. L. F.; Brum, A. C. R. Potencial de culturas de cobertura em acumular carbono e nitrogênio no solo no plantio direto e a melhoria da qualidade ambiental. Revista Brasileira de Ciência do Solo, v.25, p.189-197, 2001.

Amado, T. J. C.; Matos, A. T. de.; Torres, L. Flutuação de temperatura e umidade do solo sob preparo convencional e em faixas na cultura da cebola. Pesquisa Agropecuária Brasileira, v.25, n.4, p.625-631, 1990.

Andrade, R. da .S.; Moreira, J. A. A.; Stone, L. F.; Carvalho, J. de A. Consumo relativo de água do feijoeiro no plantio direto em função da porcentagem de cobertura morta do solo. Revista Brasileira de Engenharia Agrícola e Ambiental, v.6, n.1, p.35-38, 2002.

Andrioli, I.; Palmeri, A. J.; Chueire, F. B.; Natale, W.; Centurion, J. F. Avaliação da estrutura e da matéria orgânica do solo em áreas de plantio direto e convencional de soja sobre palha de cana-de-açúcar na região de Ribeirão Preto - SP. In:Congresso Brasileiro de Ciência do Solo, 26, 1997, Rio de Janeiro. Anais ... Rio de Janeiro: SBCS, 1997. CD Rom 
Barcelos, A. A.; Cassol, E. A.; Denardin, J. E. Infiltração de água em um latossolo vermelho-escuro sob condições de chuva intensa em diferentes sistemas de manejo. Revista Brasileira de Ciência do Solo, v.23, p.35-43, 1999.

Bianchini, A.; Magalhães, P. S. G.; Braunbeck, O. Cultivo do solo em áreas de cana crua. Revista STAB, v.19, n.5, p.3033, 2001.

Canellas, L. P.; Velloso, A. C. X.; Marciano, C. R.; Ramalho, J. F. G. P.; Rumjanek, V. M.; Rezende, C. E.; Santos, G. A. Propriedades químicas de um cambissolo cultivado com cana-deaçúcar, com preservação do palhiço e adição de vinhaça por longo tempo. Revista Brasileira de Ciência do Solo, v.27, p.935-944, 2003.

Carvalho, E. J. M.; Figueiredo, M. de S.; Costa, L. M. da. Comportamento físico-hídrico de um podzólico vermelho-amarelo câmbico fase terraço sob diferentes sistemas de manejo. Pesquisa Agropecuária Brasileira, v.34, n.2, p.257-265, 1999.

Ceddia, M. B.; Anjos, L. H. C. dos; Lima, E.; Ravelli Neto, A.; Silva, L. A. da. Sistemas de colheita da cana-de-açúcar e alterações nas propriedades físicas de um solo podzólico amarelo no estado do Espírito Santo. Pesquisa Agropecuária Brasileira, v.34, n.8, p.1467-1473, 1999.

CONAB - Companhia Nacional de Abastecimento. Revista Indicadores da Agropecuária, ano XIV, n.9, p.60, 2005.

Cruz, D. M. Plantio direto e preparo reduzido ganham terreno. JornalCana, mar., p.34, 2003.

Dalben, E. A.; Nelli, E. J.; Almeida, O. J.; Demathê, J. L. I. Plantio direto de cana-de-açúcar em solos de baixa fertilidade. Revista Álcool \& Açúcar, v.3, n.12, p.30-32, 1983.

da Ros, C. O.; Lopes, C. E. L.; Secco, D.; Pasa, L. Influência do tempo de cultivo no sistema de plantio direto nas características físicas de um Latossolo Vermelho-Escuro. Ciência Rural, v.26, n.3, p.397-400, 1996.

Ferreira, P. V. Estatística experimental aplicada à agronomia. 3.ed. Maceió: EDUFAL, 2000. 422p.

Franchini, J. C.; Borkert, C. M.; Ferreira, M. M.; Gaudêncio, C. A. Alteranções na fertilidade do solo em sistemas de rotação de culturas em semeadura direta. Revista Brasileira de Ciência do Solo, v.24, p.459-467, 2000.

Freitas, P. S. L. de; Mantovani, E. C.; Sediyama, G. C.; Costa, L. C. Efeito da cobertura de resíduo da cultura do milho na evaporação da água do solo. Revista Brasileira de Engenharia Agrícola e Ambiental, v.8, n.1, p.85-91, 2004.
Jackson, M. L. Nitrogen determinations for soil and plant tissue. In: Jackson, M. L. (ed.). Soil chemical analysis. Englewood Cliffs: Prentice Hall, 1965. p.195-196.

Jones, J. B.; Wolf, B.; Mills, H. A. Plant Analysis Handbook. A practical sampling, preparation, analysis, and interpretation guide. 1.ed. Athens: Micro-Macro Publishing Inc., 1991. 213p.

Linder, R. C. Rapid analytical methods for some of the mare commom inorganic constituints of plant tissues. Plant Physiology, v.19, p.76-89, 1944.

Malavolta, E. Avaliação do estado nutricional das plantas: Princípios e aplicações. 2.ed. Piracicaba: POTAFOS, 1997. 319p.

Mendonza, H. N. S.; Lima, E.; Anjos, L. H. C.; Silva, L. A.; Ceddia, M. B.; Antunes, M. V. M. Propriedades químicas e biológicas de solo de tabuleiro cultivado com cana-de-açúcar com e sem queima da palhada. Revista Brasileira de Ciência do Solo, v.24, p.201-207, 2000.

OPLANA - Organização de Plantadores de Cana da Região Centro-sul do Brasil. Cálculo simplificado do preço da cana-deaçúcar. Cadernos Orplana, v.5, p.1-2, 2005.

Orlando Filho, J.; Macedo, N.; Tokeshi, H. Seja doutor do seu canavial. Informações Agronômicas, v.67, p.1-16, 1994.

Raij, B. van; Cantarella, H.; Quaggio, J. A.; Furlani, A. M. C. Boletim 100: Recomendações de adubação e calagem para o Estado de São Paulo. 2.ed. Campinas: FUNDAG, 1996. 285p.

Reis Jr., R. A. Diagnose nutricional da cana-de-açúcar com uso do sistema integrado de diagnose e recomendação (DRIS). Campos dos Goytacazes: UENF, 1999. 141p. Tese Doutorado

Reis Jr., R. A.; Monnerat, P. H. Diagnose nutricional da cana-deaçúcar em Campos dos Goytacazes (RJ). Revista Brasileira de Ciência do Solo, v.26, p.367-372, 2002.

Ribeiro Júnior, J. I. Análises estatísticas no SAEG. 1.ed. Viçosa: UFV, 2001. 301p.

Santos, H. P. dos; Tomm, G. O.; Lhamby, J. C. B. Plantio direto versus convencional: Efeito na fertilidade do solo e no rendimento de grãos de culturas em rotação com cevada. Revista Brasileira de Ciência do Solo, v.19, p.449-454, 1995.

Seganfredo, M. L.; Eltz, F. L. F.; Brum, A. C. R. de. Perdas de solo, água e nutrientes por erosão em sistemas de culturas em plantio direto. Revista Brasileira de Ciência do Solo, v.21, p.287-291, 1997.

Silva, M. S. L. da; Ribeiro, M. R. Influência do cultivo contínuo da cana-de-açúcar nas propriedades químicas de solos argilosos. Pesquisa Agropecuária Brasileira, v.30, n.3, p.389-394, 1995. 